\title{
Improving Procedure Logging among Gastroenterology Trainees Using a Mobile Application
}

Jimoh LY1 and Obstein $\mathrm{KL}^{2,3 *}$

${ }^{1}$ Department of Internal Medicine, Vanderbilt University Medical Center, Nashville, TN, USA

${ }^{2}$ Division of Gastroenterology, Hepatology and Nutrition, Vanderbilt University Medical Center, Nashville, TN, USA

${ }^{3}$ Department of Mechanical Engineering, Vanderbilt University, Nashville, TN, USA

\begin{abstract}
Background: Gastroenterology (GI) fellows perform endoscopic procedures and are asked to record information regarding the procedure and their involvement. As no standard method for procedure logging exists and retrieval of data can be challenging, we have created a novel mobile device application (MDA) to accomplish this task.
\end{abstract}

Objective: To determine if a novel MDA will allow for improved endoscopic procedure logging and data retrieval

Methods: A 19-item questionnaire was created to assess the current logging practice of GI fellows at our tertiary care academic medical center. Fellows then downloaded the MDA free-of-charge from the iTunes App store. After 8 weeks of MDA use, fellows were asked to complete the same questionnaire and the NASA task load index (TLX). The study was IRB approved.

Results: $11 \mathrm{Gl}$ fellows were enrolled. Pre-MDA 7 maintained a paper log, 7 computer-based log, and 1 webbased $\log 83 \%$ of procedures completed were logged; $36.4 \%$ within $24 \mathrm{hr}$ of procedure completion. Pre-MDA, fellows estimated their Polyp Detection Rate (PDR) to be $54.5 \% \pm 18.8 \%$ and attending take-over rate (ATR) $39.25 \%$. PostMDA, $85.2 \%$ of procedures were logged $(p=0.47) ; 54.5 \%$ within $24 \mathrm{hr}(p=0.38)$. The MDA recorded PDR was $50 \% \pm$ $31 \%(p=0.74)$ and ATR was $54 \%(p=0.19)$. TLX among MDA users demonstrated very low physical demand $8.6[0$, 21], low mental demand 18.3 [14, 25], low effort 27 [10,60], and high success $84[76,100]$.

Conclusion: MDA procedure logging was efficient and successful. Data was easily retrieved and MDA use was quickly adopted. The MDA may be a useful tool for recording and retrieving procedure logs in a standard fashion.

\section{Keywords: Gastroenterology; Mobile application; NASA}

\section{Background}

Gastroenterology (GI) training programs face a challenge in regard to accurate tracking and reporting of trainee endoscopy activity-related data. There is currently no standardized manner of collecting data on common procedures like colonoscopy and esophagogastroduodenoscopy (EGD). Training programs rely on varying electronic medical records (EMR) related databases or trainee self-reporting to provide an estimate of how many procedures their fellows have completed. Data is housed in different silos (i.e., Provation $^{\mathrm{nw}}$, New Innovation ${ }^{\mathrm{m}}$, EPIC systems, MS Excel spread sheets, etc.) making aggregation and analysis difficult [1]. With the new Accreditation Committee for Graduate Medical Education (ACGME) requirements on procedure reporting, many of the data collection tools are not collecting the right type of data or the same type of data [2]. Before the recent switch to the ACGME's next accreditation system [3], the lack of documentation of the procedural experience of trainees was one of the more common Residency Review Committee (RRC) citations $[4,5]$. Additionally, trainees are not certain of how many procedures they have completed and are unaware of their progress to procedural proficiency-let alone how they compare with their peers within their own training program and the country at large. Lastly, a program director should be able to have a real-time method for determining the quantity and type of procedure that each fellow has completed. The program director should also be able to evaluate the level of proficiency of each trainee based on certain pieces of data collected for each procedure logged. This is especially important in a subspecialty where procedural mastery has been gauged by number of supervised procedures completed [6]. In 2009, the ACG and ASGE collaborated to create a national GI endoscopy data repository for storage and maintenance of endoscopy quality metrics [7]. This tool serves the needs of physicians from hospitals, universities, ambulatory surgery centers, and office-based endoscopy units nationwide. In May 2014, CMS approved GIQuIC as a Physician Quality Reporting System (PQRS) Qualified Clinical Data Registry (QCDR) [8]. While this serves an important role in creating a benchmark for practicing endoscopists, it does not assess trainee needs and it does not exist on a mobile platform.

The use of mobile phone or personal digital assistant (PDA) based solutions in healthcare have become commonplace and have increased at an exponential rate over the past decade [9]. As a result there are now almost 20,000 health related apps on the Apple App store $^{\infty}$ [10]. However, in the field of academic medicine, adoption of this technology has not been as robust. There are sparse reports of electronic logging by Emergency Medicine residents [11,12]. Mobile device applications (MDA) have been shown to be effective in tracking the number of bedside procedures residents are performing in the emergency departments in real-time. Hand-held computers have also been used successfully by fourth year medical students to log the type of cases observed on a given rotation [13]. Multiple studies have shown that these tools improve compliance, timeliness of procedural

*Corresponding author: Obstein KL, Division of Gastroenterology, Hepatology and Nutrition, Vanderbilt University Medical Center, Nashville, TN-37232-5280, USA, Tel: 6153220128; Fax: 6153438174; E-mail: keith.obstein@vanderbilt.edu

Received November 19, 2015; Accepted January 26, 2016; Published January 29, 2016

Citation: Jimoh LY, Obstein KL (2016) Improving Procedure Logging among Gastroenterology Trainees Using a Mobile Application. J Comput Sci Syst Biol 9: 023-027. doi:10.4172/jcsb.1000216

Copyright: $\odot 2016$ Jimoh LY, et al. This is an open-access article distributed under the terms of the Creative Commons Attribution License, which permits unrestricted use, distribution, and reproduction in any medium, provided the original author and source are credited. 
logging and results in more complete and useful documentation [14]. In addition, MDAs have also been used effectively to log procedures in a critical care setting [15] and in general surgery resident training [16]. The caveat with those studies is that not all end users were receptive to change and constant technology support and training was needed.

Our aim was to create and test, in an academic GI training program, an MDA (called eLog) that can be used easily to collect data on trainee endoscopic activity. We hypothesized that this tool can be successfully adopted, improve timeliness and completeness of data documentation, and will be acceptable to the users.

In building the eLog app, we incorporated data that included endoscopic procedure quality metrics (i.e., indication for procedure, type of sedation, intervention performed, cecal intubation time, total procedure time, farthest extent reached, farthest extent reached independently, type of attending assistance required, polyp detection rate (PDR) and adenoma detection rate (ADR)) as outlined in published American Society for Gastrointestinal Endoscopy (ASGE) guidelines $[17,18]$. Additionally, with an automated monthly report as a feedback product, the app needed to provide useful information on proficiency. Therefore, it was important to design an MDA that simultaneously collected data that could be used to assess quality of endoscopic procedures [19] while also assessing data that may suggest competency of the trainee (i.e., farthest extent reached independently and type of attending assistance required).

Our study was designed to evaluate the impact of the eLog mobile application in addressing: timeliness of data entry, ease of use of the app, and the quality of the data reported.

\section{Methods}

\section{Mobile application}

eLog is an iOS based software application that allows users to register their copy of the app and, upon their registration being approved, to log details of individual procedures performed by gastroenterologists without any protected health information (PHI). The application also allows users to upload the logged procedures from their IOS device to a central database server and retrieve that data at a later date via an automated monthly emailed report of all of their procedures. An administrator website allows users assigned with administering this program to approve registrations, fix registration data, and generate and email reports of uploaded procedures. "This app is available for download free of charge at the iTunes app store (https://itunes.apple. com/us/app/elog/id811747860? $\mathrm{mt}=8)$ ".

\section{Study}

We enrolled 11 clinical GI fellows in an academic tertiary hospital. Using a 19 item questionnaire (the questionnaire was peer-validated for this population of respondents and distributed via internet for selfadministration), the fellows were asked a series of questions assessing their current logging practices, timeliness of data entry after endoscopy procedure, knowledge of endoscopy volume, percentage of manual take over by attending, polyp detection rate (PDR) and adenoma detection rate (ADR). This same instrument was used to survey the fellows again 8 weeks after implementation of the MDA.

A modified NASA task load index (NASA Ames Research Center, Moffett Field, CA, USA) [20] was used to evaluate the ease of use of the MDA. This is a reliable and validated tool that assesses the ease of use of new technological tools using 4 categories: physical demand, mental demand, effort used and success achieved [21].
The study was considered exempt from informed consent by our institution research board (IRB) [IRB \# 131665].

\section{Data analysis}

After completion of the study, data from the survey responses were transferred to a Microsoft Excel spreadsheet (Microsoft, Redmond, WA). Certain data like actual polyp detection rate (PDR) and attending take over rate (ATR) were extracted from the eLog database. The survey was analyzed with descriptive statistics and comparisons between groups (pre-MDA and post-MDA; MDA users and MDA non-users) were performed using means, standard deviations, and t test statistics.

\section{Results}

Of the 11 fellows ( 5 females), 7 kept a paper-based log, 7 computerbased $\log$, and 1 web-based $\log$ before the MDA was launched. While a majority of the fellows only kept one logging modality, 4 fellows kept $2 \log$ modalities (mostly a paper based log which was later copied into a computer based log). 5 downloaded the MDA. Of the 6 who did not, 3 did not own an iOS device and 3 declined to adopt a new method of logging procedures Pre-MDA, $84.9 \%$ of procedures completed were logged and $36 \%$ logged $\leq 24$ hours of procedure completion. Fellows estimated their PDR to be $54.5 \% \pm 18.8 \%$ and attending take-over rate to be $39.25 \%$. After 8 weeks of MDA use, 3 fellows maintained a paper $\log , 5$ computer-based log and 5 kept web based log (Figure 1). Post-MDA, $85.2 \%$ of procedures were logged $(\mathrm{p}=0.47)$ and $54.5 \%$ were logged $\leq 24$ hours of procedure completion (Figure 2). PDR was reported from survey data at $56.6 \% \pm 16.9 \%$ (Figure 3 ) and measured by the MDA at $50 \% \pm 31 \%(\mathrm{p}=0.74)$. Attending take over rate reported by all fellows post-PDA was $19.25 \%$. Among first year fellows, the rate was reported at $38 \%$ but MDA measured at $54 \%(\mathrm{p}=0.19)$.

Modified NASA TLX among MDA users demonstrated very low physical demand $8.6[0,21]$, low mental demand $18.3[14,25]$, low effort $27[10,60]$, and high success $84[76,100]$. In the 8 wk period, 201 endoscopic procedures ( 100 colonoscopies, 83 EGDs, 5 PEG tube placements, 2 ERCPs and 11 other procedures) were logged (Table 1).

\section{Discussion}

The results above demonstrate that a MDA can be used by GI trainees to log their endoscopic procedures. This innovation can also improve timeliness of logging as shown by the increase in percentage of procedures logged within $24 \mathrm{hrs}$ of completion. PDRs reported by fellows who used the MDA when compared to the PDRs derived from data entered showed a statistically insignificant difference $(69.5 \% v s$ $50 \% ; \mathrm{p}=0.74$ ). While data entered into the database by the fellows are not individually verified, the proximity of measured PDR to reported

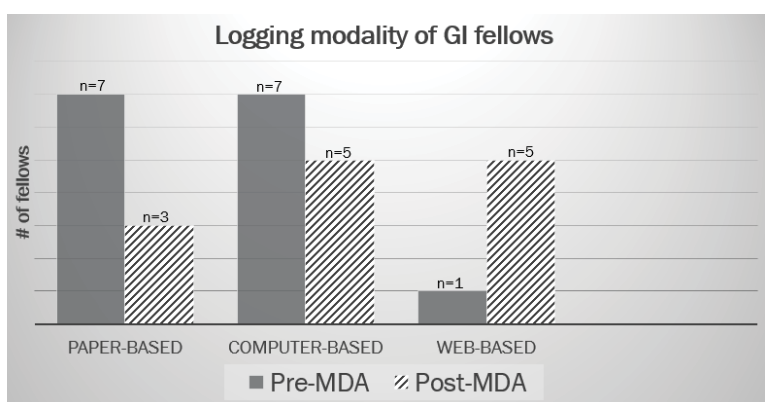

Figure 1: Effect of MDA on GI fellows logging modality. There is a trend towards electronic methods of logging post introduction of MDA. 
Citation: Jimoh LY, Obstein KL (2016) Improving Procedure Logging among Gastroenterology Trainees Using a Mobile Application. J Comput Sci Syst Biol 9: 023-027. doi:10.4172/jcsb.1000216

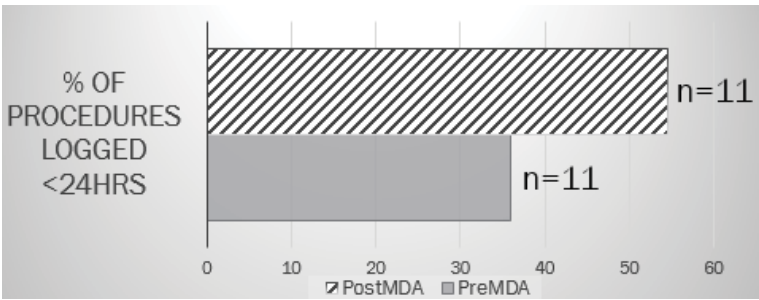

Figure 2: Percentage of procedures logged within $24 \mathrm{~h}$ increased from $36 \%$ to $54.5 \%$ after the introduction of eLog.

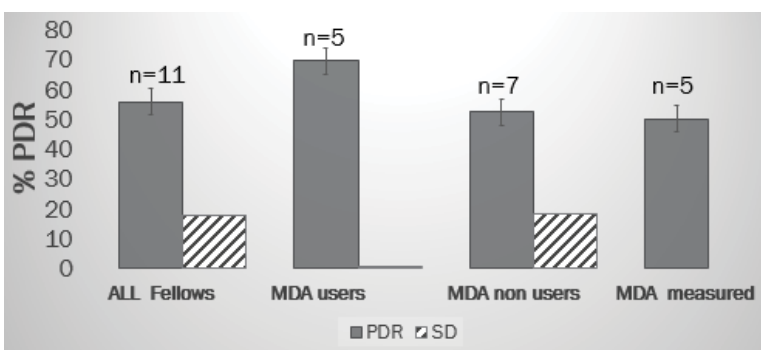

Figure 3: Comparison of Polyp Detection Rates (PDR). PDR among MDA users appear higher than non-users. This is most likely because most of the MDA users were first year fellows who did more procedures during the 8 week period. The MDA measured bar refers to the derived PDR from the logs entered.

\begin{tabular}{|c|c|c|c|}
\hline & Physical Demand $\mathbf{n = 5}$ & Mental Demand $\mathbf{n = 5}$ & Efforts=5 \\
\hline Max & 21 & $\mathbf{2 5}$ & 60 \\
\hline Min & 0 & 14 & 100 \\
\hline Mean & 8.6 & 18.3 & $\mathbf{7 6}$ \\
\hline St Dev & 10.9 & 5.8 & 27 \\
\hline
\end{tabular}

Table 1: The modified NASA task load index scores showing that with low physical and mental demand, users were successfully logging their procedures.

(A)

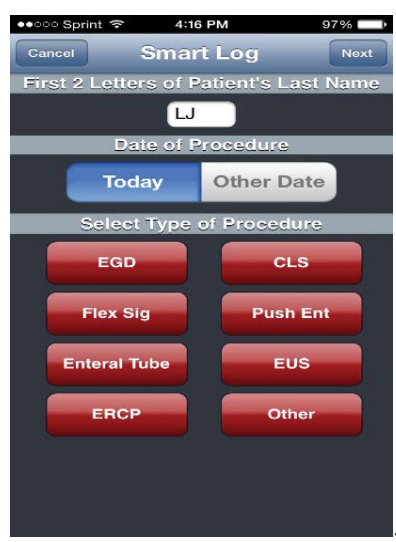

(B)

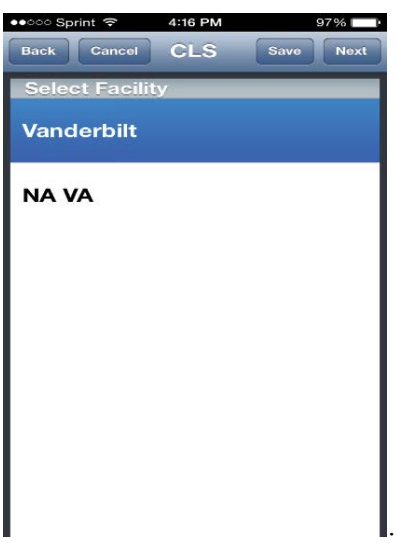

(C)

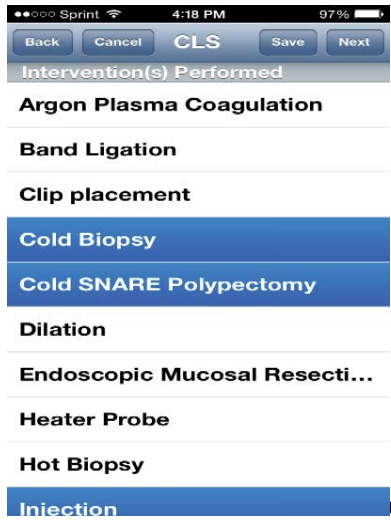

(D)

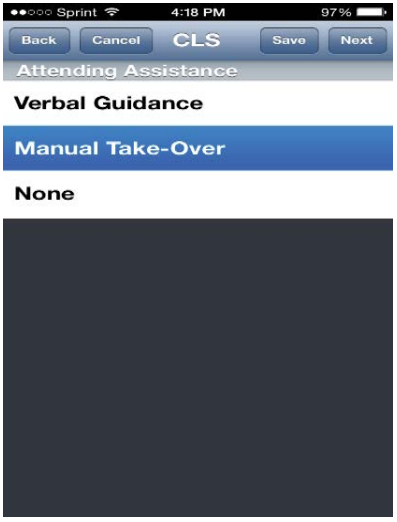

(E)

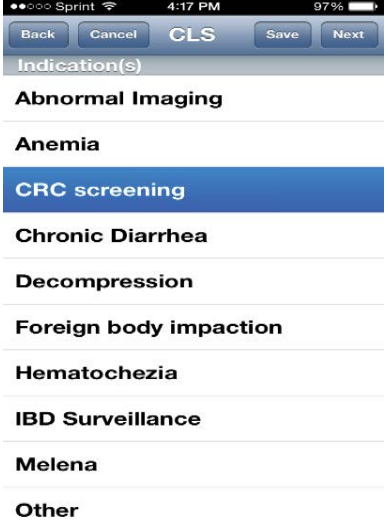

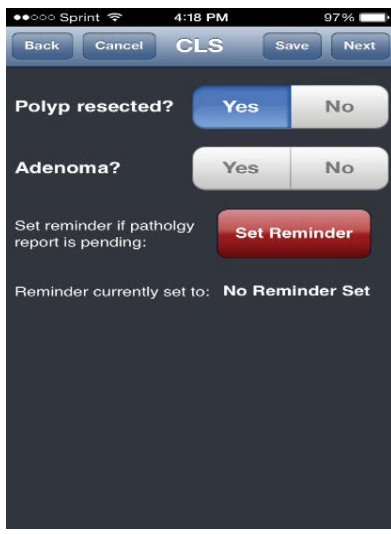

(F)

Figure 4: Screenshots of elog. A) The index page of the app showing the field for entering 2 intials of the patient's name, date procedure was performed and the different endoscopic procedures the app is capable of logging. CLS refers to colonoscopy. B) This page shows the option of using the app to log data on procedures completed at multiple facilities. C) This is the page where users select the appropriate indication for the procedure they are logging. D) This page prompts the user to enter any interventions performed during the procedure; multiple interventions can be entered at once. E) This page asks about the level of attending assistance required by the trainee during the procedure. F) This page asks if a polyp was resected and also if it was adenomatous; if pathology results are pending, there is an option for the user to set a reminder on the mobile device via the app. 
PDR is reassuring. eLog provided users and program directors an objective method of calculating PDR. In addition to measuring PDR, a potentially reliable surrogate for Adenoma Detection Rates (ADR) [22,23], eLog reminds users to follow up on pathology results in order to accurately determine if a polyp was adenomatous (as shown in Figure 4f). A 1998 study on emergency medicine (EM) residents showed that only $60 \%$ of procedures performed are logged when done manually [24]. This suggests that there is gross under-reporting of procedures performed. Recent efforts by the ACGME to improve logging practices, more available tools (laptops, clinical work-stations, etc.) and requests to view procedure logs by employers are likely to account for the $84.9 \%$ logging rates our GI fellows report in this study.

This study also introduces a variable that may assist in competency assessment for training GI fellows- attending take over rate (ATR). We define this as the percentage of total procedures that a trainee has to physically hand the endoscope over to a supervising attending. According to many experts, this rate should be less than $15 \%$ for senior trainees [25].

We did not verify data entered into the MDA through auditing the EHR of the patients or institutions of where the procedure was performed. We relied on the similarities between the numbers reported on the survey (PDR, ADR and attending take over rate) and numbers derived from the MDA. Ultimately, program directors will have to rely on the integrity of their fellows as is the case currently. The scope of our study was limited to testing the feasibility of adoption among a small number of trainees. In order to verify accuracy of data entered, a larger study in an environment where eLog has been in use for some time will be undertaken. More so, our current design represents real life scenarios as regular auditing of procedures logged by physicians is not commonplace. Additionally, our sample size was limited to the number of trainees in our program. This may provide useful data for our program specifically but may not make our results generalizable to other programs and therefore multi-center studies are being planned.

\section{Conclusion}

Our study demonstrates that an MDA can be adapted into use by trainees as the primary method of procedure logging and may change logging habits in a positive manner through electronic/web-based data platform with instant recall of data. The NASA task load index scores indicate that fellows found eLog easy to use with little mental or physical demand. Trainees were able to achieve high rates of user success for data entry (even in the initial familiarization stage). With more eLog experience, the amount of effort, mental demand and physical demand would be expected to decrease. As of February 2015, eLog has recorded over 1300 procedures in 11 months of use and has expanded to 4 different training programs in the country. This tool has the potential to help create a centralized national database that will allow for utilization of data by fellows, programs and GI societies to improve/enhance endoscopic training and trainee specific quality reporting metrics. Such a tool will enable the development of generalizable standardized learning curves and milestones--as recently posited by the ASGE training committee [26]. Further studies are underway to test the MDA in multiple sites and include EHR audits for verification of data entered.

\section{Acknowledgements}

This study was presented at a poster session on Oct 20, 2014 at the American College of Gastroenterology (ACG) national meeting in Philadelphia, PA, USA. The eLog app development was funded by a grant from the Vanderbilt Center for Technology Transfer and Commercialization (CTTC).

\section{References}

1. Delvaux MM, Crespi M, Armengol-Miro JR, Hagenmüller F, Teuffel W (1999) The GASTER project: building a computer network in digestive endoscopy: the experience of the European Society for Gastrointestinal Endoscopy. Gastrointestinal Endoscopy Application for Standards in Telecommunication Education and Research. J Clin Gastroenterol 29: 118-126.

2. Moskowitz EJ, Nash DB (2007) Accreditation Council for Graduate Medica Education competencies: practice-based learning and systems-based practice. Am J Med Qual 22: 351-382

3. Nasca TJ, Philibert I, Brigham T, Flynn TC (2012) The next GME accreditation system--rationale and benefits. N Engl J Med 366: 1051-1056.

4. Carter W, Meyer L (2011) Session 21-specialty update: emergency medicine. Accredidation Council for Graduate Medical Education (ACGME) 2011 Annual Education Conference. Nashville, TN.

5. Authors not listed (2009) Impact statement for revisions to the program requirements for graduate medical education in internal medicine, effective July 1, 2009, Chicago [Link]. Accreditation Council for Graduate Medical Education, September 2008.

6. Northup PG, Argo CK, Muir AJ, Decross AJ, Coyle WJ, et al. (2013) Procedura competency of gastroenterology trainees: from apprenticeship to milestones. Gastroenterology 144: 677-680

7. GIQuIC (2015) What is GIQulC? [http://giquic.gi.org/what-is-giquic.asp], FAQs page on GIQuIC website.

8. Physician Quality Reporting System Qualified Clinical Data Registries (2014) [Link], CMS official publication.

9. Ozdalga E, Ozdalga A, Ahuja N (2012) The smartphone in medicine: a review of current and potential use among physicians and students. J Med Internet Res 14: e128.

10. Timothy Aungst (2013) Apple app store still leads Android in total number of medical apps. http://www.imedicalapps.com/2013/07/apple-android-medicalapp/. Published on July 12, 2013.

11. Rosenthal M, Wolford RW (2000) Resident procedure and resuscitation tracking using a palm computer. Acad Emerg Med 7: 1171.

12. Bird SB, Zarum RS, Renzi FP (2001) Emergency medicine resident patient care documentation using a hand-held computerized device. Acad Emerg Med 8: $1200-1203$.

13. Penciner R, Siddiqui S, Lee S (2007) Emergency medicine clerkship encounter and procedure logging using handheld computers. Acad Emerg Med 14: 727 31.

14. Kho A, Henderson LE, Dressler DD, Kripalani S (2006) Use of handheld computers in medical education. A systematic review. J Gen Intern Med 21 531-537.

15. Martinez-Motta JC, Walker R, Stewart TE, Granton J, Abrahamson S, et al. (2004) Critical care procedure logging using handheld computers. Crit Care 8: R336-342.

16. Fischer S, Lapinsky SE, Weshler J, Howard F, Rotstein LE, et al. (2002) Surgical procedure logging with use of a hand-held computer. Can J Surg 45: 345-350.

17. Rex DK, Petrini JL, Baron TH, Chak A, Cohen J, et al. (2006) Quality indicators for colonoscopy. Gastrointest Endosc 63: S16-28.

18. Cohen J, Safdi MA, Deal SE, Baron TH, Chak A, et al. (2006) Quality indicators for esophagogastroduodenoscopy. Gastrointest Endosc 63: S10-15.

19. Eisen GM, Baron TH, Dominitz JA (2002) Methods of granting hospital privileges to perform gastrointestinal endoscopy. Gastrointest Endosc 55: 780-783.

20. Obstein KL, Patil VD, Jayender J, San José Estépar R, Spofford IS, et al. (2011) Evaluation of colonoscopy technical skill levels by use of an objective kinematic-based system. Gastrointest Endosc 73: 315-321.

21. Hart SG, Staveland LE (1988) Development of NASA-TLX (Task Load Index) Results of empiricaland theoretical research. In Hancock PA and Meshkati N (Eds.) Human Mental Workload. Amsterdam: North Holland Press.

22. Francis DL, Rodriguez-Correa DT, Buchner A, Harewood GC, Wallace M (2011) Application of a conversion factor to estimate the adenoma detection rate from the polyp detection rate. Gastrointest Endosc 73: 493-497. 
Citation: Jimoh LY, Obstein KL (2016) Improving Procedure Logging among Gastroenterology Trainees Using a Mobile Application. J Comput Sci Syst Biol 9: 023-027. doi:10.4172/jcsb.1000216

23. Boroff ES, Gurudu SR, Hentz JG, Leighton JA, Ramirez FC (2013) Polyp and adenoma detection rates in the proximal and distal colon. Am J Gastroenterol 108: 993-999.

24. Langdorf MI, Montague BJ, Bearie B, Sobel CS (1998) Quantification of procedures and resuscitations in an emergency medicine residency. J Emerg Med 16: 121-127.
25. Sedlack RE (2011) Training to competency in colonoscopy: assessing and defining competency standards. Gastrointest Endosc 74: 355-366.

26. Sedlack RE, Coyle WJ, Obstein KL, Al-Haddad MA, Bakis G, et al. (2014) ASGE's assessment of competency in endoscopy evaluation tools for colonoscopy and EGD. Gastrointest Endosc 79: 1-7. 